\title{
IS RHTMD A NEW PREDICTOR FOR ASSESSMENT OF DIFFICULT INTUBATION IN NON-OBESE PATIENTS?
}

\author{
Mamta Harjai1, Priyesh Bhaskar², Shobhit Saxena ${ }^{3}$, Shivani Rastogi ${ }^{4}$, Prithvi Kumar Singh ${ }^{5}$ \\ ${ }^{1}$ Associate Professor, Department of Anaesthesia, RMLIMS, Lucknow, Uttar Pradesh, India. \\ ${ }^{2}$ Associate Professor, Department of Anaesthesia, Career Institute of Medical Sciences, Lucknow, Uttar Pradesh, India. \\ $3 J u n i o r$ Resident, Department of Anaesthesia, RMLIMS, Lucknow, Uttar Pradesh, India. \\ ${ }_{4}^{4}$ Associate Professor, Department of Anaesthesia, RMLIMS, Lucknow, Uttar Pradesh, India. \\ ${ }^{5 S S T A}$, Department of CFAR (Cytogenetics Unit), KGMU, Lucknow, Uttar Pradesh, India.
}

\section{ABSTRACT}

\section{BACKGROUND}

The recognition of difficult intubation during pre-operative check-up is very important for the anaesthesiologist. Various anatomical parameters assist in predicting difficult intubation. Till date, there are no predictors available to precisely assess the risk of difficult intubation, pre-operatively.

Therefore, we aim to identify the adequacy of predictors for preoperative assessment of difficult intubation.

\section{MATERIALS AND METHODS}

After ethical approval of Institutional Ethics Committee, a total of 200 non-obese patients (Body mass index less than or equal to 30) were recruited in this prospective observational study after obtaining informed consent. Mouth Opening (MO), Modified Mallampati Grading (MMG), neck circumference (cm), Thyromental Distance (TM), Sternomental Distance (SM), Neck Movement (NM), Neck Circumference (NC) and Ratio of Height to Thyromental Distance (RHTMD) were measured pre-operatively. In each patient, validated Intubation Difficulty Score (IDS score) was assessed intraoperatively by the anaesthetist. All patients were divided into two groups on the basis of easy (IDS score $<5$ ) and difficult intubation (IDS score $\geq 5$ ). Multivariate logistic regression analysis including all variables was used to create a predictive model.

\section{RESULTS}

Laryngoscopy was difficult in $12.0 \%$ of the patients. The MO, MMG, NM, NC, TM, SM, NC/TM were significantly different in between easy and difficult intubation. The Area Under Curve (AUC) in ROC for the TM, SM, NC/TM, RHTMD and MPC were 0, 270, 0.138, $0.848,0.807$ and 0.699 , respectively. Among all indices, NC/TM and RHTMD were found to have high sensitivity and specificity. NC/TM was showing maximum area under the curve on ROC curve (AUC) followed by RHTMD.

\section{CONCLUSION}

Among non-obese patients, NC/TMD ratio and RHTMD can be used for better predictor of difficult intubation, pre-operatively.

\section{KEY WORDS}

Airway Management; Intubation; Laryngoscopy; Risk Assessment; Intubation Difficulty Scale.

HOW TO CITE THIS ARTICLE: Harjai M, Bhaskar P, Saxena S, et al. Is RHTMD a new predictor for assessment of difficult intubation in non-obese patients? J. Evolution Med. Dent. Sci. 2018;7(38):4157-4160, DOI: 10.14260/jemds/2018/930

\section{BACKGROUND}

Airway management is a major concern to anaesthesiologist and can contribute to perioperative mortality and morbidity if not managed in time.[1] Upto $30 \%$ of anaesthetic deaths have been stated in cases of compromised poorly managed airway. Hence, the recognition of this problem during preoperative anaesthetic check-up is of headmost importance for the anaesthesiologist. Many scoring indices for determination of difficult intubation or difficult laryngoscopy based on various parameters either as a single parameter or in combination have been proposed over time. ${ }^{[2-4]}$ Mallampati grading 2 was based on the visibility of anatomical structures of oral cavity,

'Financial or Other Competing Interest': None.

Submission 13-08-2018, Peer Review 04-09-2018,

Acceptance 12-09-2018, Published 17-09-2018.

Corresponding Author:

Dr. Priyesh Bhaskar,

Associate Professor

Department of Anaesthesia,

Career Institute of Medical Sciences,

Lucknow, Uttar Pradesh, India.

E-mail: priyeshlpsc@gmail.com

DOI: $10.14260 /$ jemds $/ 2018 / 930$ which underwent modification by Samsoon and Young in 1987.[3] Similarly, Wilson et al (1988) developed a score based on various physical factors. ${ }^{[4]}$ But none of these scores were found to have similar diagnostic accuracy, their results varied in different studies. As a result, there are no predictors available single or in combination, which can precisely assess the risk of difficult intubation pre-operatively. Therefore, we aim to compare the adequacy of various parameters used for assessment of difficult intubation and to identify the parameter with highest specificity and sensitivity.

\section{MATERIALS AND METHODS}

After obtaining Institutional Ethics Committee approval, this prospective, observational study was carried out over a duration of two years at Dr. Ram Manohar Institute of Medical Sciences, Lucknow. This study was conducted in 200 patients (18 - 72 years of age) without obvious airway pathology. All patients belonged to the American Society of Anesthesiology (ASA) class I or II and were scheduled for elective surgery that required general anaesthesia. Pregnant women, obese patients, patients with congenital deficiencies or airway with difficult anatomy were excluded. 
All patients were assessed on the day before surgery by a single observer. Airway assessment was performed preoperatively based on clinical screening tests and noted.

\section{Following Parameters were Assessed-}

Mouth Opening (MO), Modified Mallampati Grading (MMG), Neck Movement (NM), Neck circumference ( $\mathrm{cm}$ ) at the level of cricoid cartilage was evaluated. HM distance $(\mathrm{cm})$ is the distance between hyoid bone and mentum. TMD is distance from mentum to thyroid notch and Sternomental distance (cm) was measured as distance between upper border of sternomanubrial joint to the mentum. Measurement of all the above three distances were done in extended neck position.

The ratios of NC/TM and Ratio of Height to Thyromental Distance (RHTMD) were calculated. In the operation theatre, the patient was placed supine and head in the sniffing position with the use of pillows such that the external auditory meatus and the sternal notch are aligned in same line. Patient was induced with propofol $(2 \mathrm{mg} / \mathrm{kg})$ and neuromuscular agent atracurium $(0.5 \mathrm{mg} / \mathrm{kg})$ was then given to all patients. After 3 - 5 mins, laryngoscopy was performed using a laryngoscope with a Macintosh curved blade. Laryngoscopy was performed by senior resident in all cases, since ours is a teaching institute.

The assessment of difficult intubation was done as per intubation difficulty scale, which was recorded by the senior anaesthetist who was blinded to the study. ${ }^{[5]}$

\section{The Grading of IDS has been done as follows-}

- N1: Number of added intubation attempts.

- N2: Number of added operators.

- N3: Number of alternative intubation methods.

- N4: Laryngeal view as described by Cormack and Lehane's grading (Grade 1= N4-0; Grade 2= N4-1; Grade $3=\mathrm{N} 4-2$; Grade 4= N4-3).[6]

- N5: Force applied to lift larynx during laryngoscopy (N50 if inconsiderable and N5-1 if considerable).

- N6: External laryngeal pressure needed for improving laryngeal exposure (N6-0 if no external pressure or only the Sellick manoeuvre was required and N6-1 if external laryngeal pressure was applied).

- N7: Position of the vocal cords during intubation (N7-0 if vocal cords are abducted or not visible and N7-1 if vocal cords are adducted). The IDS score is the total sum of N1 through N7.

A score of 0 means intubation under optimal conditions. The sample population in our study was described further into two groups according to the IDS (intubation difficulty score). Those with an IDS score of $\geq 5$ were characterised as difficult and $<5$ as easy respectively.

\section{Statistical Analysis}

SPSS version 10.0 was used for statistical analysis. Data was presented as mean (standard deviation, range). Multivariate analysis was used to predict independent risk factors. Receiver Operating Characteristic Curve analysis (ROC analysis) was performed for the airway assessment tests. The area under the ROC curve (AUC) was calculated and p-value $<0.05$ was considered significant. The sensitivity, specificity, Positive Predictive Value (PPV) and Negative Predictive Value (NPV) was also calculated.

\section{RESULTS}

In our study, data from 200 patients who were scheduled for surgery under general anaesthesia was evaluated. Table 1 shows the demographic features and airway profile of the study population. Out of 200 patients 24 patients showed difficulty in intubation, which was measured according to Intubation Difficulty Scale (IDS). Hence, incidence was found out to be $12 \%$.

Based on difficulty scale, patients were divided into two groups: easy if scoring is below 5 and difficult if above and equal to 5. Two groups were compared for demographic variables and various airway clinical parameters. Binary univariate logistic regression analysis was used to compare above variables between two groups (Table 2). Variables like MO, TM, SM, NC/TMD, RHTMD ( $p<0.001)$ were found to be significant in relation to group with IDS $>5$.

Table 3 shows Binary multivariate logistic regression (Forward-Wald) analysis for finding independent risk factors. From this analysis, we found that three variables were considered significant for assessment of difficult intubation. First variable RHTMD was found to be of statistical significance as an independent risk factor with odds ratio of 37 and $\mathrm{p}$-value $=0.001$.

Other independent predictor was NC/TM ratio (OR-14) and p-value $=0.001$. Figure 4 shows the ROC curve for various variables like NC/TM, RHTMD and MMG. ROC curve is a statistical graph to represent the sensitivity and specificity of any test and for what extent the test is diagnostic. Diagnostic accuracy is directly proportional to area under curve. It was found that RHTMD had larger area under the curve than Mallampati score. AUC 0.807 while AUC for NC/TMD came out to be 0.848 , which was more than Mallampati and RHTMD. Table 4 shows the sensitivity, specificity and PPV of various variables. The cut-off values of various variables like TM, SM, NC/TM and RHTMD are also shown. Above these cutoff values, the test becomes most sensitive and most specific. Cut-off value of RHTMD was 21.6.

\begin{tabular}{|c|c|c|}
\hline Parameter & Mean & \pm SD \\
\hline Age (year) & 45.2 & 15.8 \\
\hline Sex ratio (male/female) & $106 / 94$ & - \\
\hline Weight (kg) & 58.65 & 14.31 \\
\hline Height $(\mathrm{cm})$ & 156.97 & 10.30 \\
\hline $\mathrm{BMI}(\mathrm{kg} / \mathrm{m} 2)$ & 23.90 & 5.30 \\
\hline Mouth Opening & 2.87 & 0.32 \\
\hline Mallampati Grade (I/II) & $145 / 47$ & - \\
\hline Neck movement (NM) A/R & $180 / 20$ & - \\
\hline Neck circumference (NC) & 35.77 & 5.02 \\
\hline Hyomental distance (HM) & 5.1 & 0.92 \\
\hline Thyromental distance (TM) & 7.21 & 1.25 \\
\hline NC/TMD & 5.10 & 1.10 \\
\hline NC/SM & 2.38 & 0.56 \\
\hline $\begin{array}{l}\text { Ratio of height to thyromental } \\
\text { distance }\end{array}$ & 22.45 & 4.31 \\
\hline Intubation Difficulty Scale (IDS) & 2.02 & 2.55 \\
\hline \multicolumn{3}{|c|}{ Table 1. Patient Characteristics } \\
\hline
\end{tabular}

Data are represented as mean $\pm \mathrm{SD}, \mathrm{n}(\%)$ and ratio, $\mathrm{SD}=$ Standard deviation. 


\begin{tabular}{|c|c|c|c|}
\hline Parameter & $\begin{array}{c}\text { Easy } \\
(\text { IDS }<5) \\
(n=176)\end{array}$ & $\begin{array}{l}\text { Difficult } \\
(\text { IDS }>5) \\
(n=24)\end{array}$ & P-value \\
\hline Age ( & $44.56 \pm 16.20$ & $49.50 \pm 11.93$ & .181 \\
\hline $\begin{array}{c}\text { Sex ratio } \\
\text { (male/female) }\end{array}$ & $\begin{array}{c}93 \\
(52.84 \%) / 83 \\
(47.16 \%)\end{array}$ & $\begin{array}{c}13(54.17 \%) / 11 \\
(45.83 \%)\end{array}$ & 0.855 \\
\hline Weig & $57.97 \pm 13.44$ & $63.58 \pm 19.14$ & 0.071 \\
\hline Heig & $157.18=$ & $155.46 \pm 9.39$ & 0.445 \\
\hline BMI $(\mathrm{kg} / \mathrm{l}$ & $23.57 \pm$ & $26.23 \pm 6.67$ & $0.021^{*}$ \\
\hline Mouth & $2.93 \pm 0.23$ & $2.40 \pm 0.49$ & $<0.001^{*}$ \\
\hline $\begin{array}{r}\text { Mallamp } \\
\text { (I/ }\end{array}$ & $135 / 38$ & $10 / 9$ & $0.02^{*}$ \\
\hline $\begin{array}{r}\text { Neck M } \\
(\mathrm{NM}\end{array}$ & $161 / 15$ & $18 / 6$ & $0.025^{*}$ \\
\hline $\begin{array}{r}\text { Neck Circl } \\
(\mathrm{N} \\
\end{array}$ & $35.31 \pm 4.76$ & $39.17 \pm 5.62$ & $<0.001^{*}$ \\
\hline $\begin{array}{r}\text { Hyomenta } \\
\text { (H }\end{array}$ & $5.19 \pm 0.87$ & $4.40 \pm 0.94$ & $0.003^{*}$ \\
\hline $\begin{array}{l}\text { Thyr } \\
\text { Dista }\end{array}$ & $7.33 \pm 1.20$ & \pm 1.29 & 0.00 \\
\hline NC/TI & $92 \pm$ & $4 \pm 1.31$ & $0.001^{*}$ \\
\hline $\begin{array}{l}\text { Ratio of Height to } \\
\text { Thyromental } \\
\text { Distance (RHTMD) }\end{array}$ & $21.74 \pm 3.78$ & $24.75 \pm 3.81$ & $<0.001^{*}$ \\
\hline \multicolumn{4}{|c|}{$\begin{array}{c}\text { Table 2. Binary Univariate Logistic Regression comparing } \\
\text { patients with an IDS Score < } 5 \text { (Easy) and patients with an } \\
\text { IDS Score } \geq 5 \text { (Difficult) Parameters }\end{array}$} \\
\hline
\end{tabular}

\begin{tabular}{|c|c|c|c|c|}
\hline Test & Sensitivity & Specificity & PPV & NPV \\
\hline $\mathrm{TM} \leq 6.5 \mathrm{~cm}$ & 62.5 & 66.67 & 93.22 & 19.51 \\
\hline $\mathrm{NC} / \mathrm{TM} \geq 5.0$ & 78.4 & 75.0 & 98.6 & 36.7 \\
\hline RHTMD $>21.6$ & 81.2 & 83.3 & 97.3 & 37.7 \\
\hline $\begin{array}{c}\text { Mallampati } \\
\text { Score III or IV }\end{array}$ & 89.8 & 75.0 & 96.3 & 50.0 \\
\hline
\end{tabular}

Table 4. Test for Difficult Intubation. Data presented as Percentages. TM, Thyromental Distance; NC/TM, Ratio of Neck Circumference to Thyromental Distance; RHTMD, Ratio of Height to Thyromental Distance, PPV, Positive Predictive Value; NPV, Negative Predictive Value

\section{DISCUSSION}

In this observational study, the incidence of difficult intubation was observed to be $12 \%$. Various studies showed variable results. The incidence varied between $7-17 \% .{ }^{[7,8]}$ The study by Garg and Dua et al (2015) showed the incidence of $24.6 \% .{ }^{[7]}$ The variability in incidence could be due to many factors like different anatomical measurements among different population, use of different blades, expertise in laryngoscopy and degree of muscle relaxation.

In our study, NC/TMD and RHTMD were found to be independent factors for assessment of difficult intubation. While analysing results of ROC curve, greater area under curve was found for NC/TMD followed by RHTDM and Mallampati score. Though sensitivity, specificity, positive and negative predictive values of the RHTDM were more than NC/TMD, i.e. $81.2 \%, 83.3 \%, 97.3 \%$ and $37.7 \%$ respectively, while sensitivity of NC/TMD is $75 \%$, specificity $78.4 \%$ with PPV of 98.6 and NPV of $36.7 \%$. Cut-off value was 5 in our study, which corroborates with other studies. Our results are consistent with the results of study by Schmitt et al (2002). They reported that RHTMD has good predictive value for predicting difficult laryngoscopy than TMD.[9] AUC of RHTMD was greater than TMD alone. Neck circumference at the thyroid cartilage is an important prognosticator of difficult laryngoscopy in both obese and non-obese in many researches.[10,11] In recent studies, especially in obese patients and in obstructive sleep apnoea patients, NC/TMD is emerging as a good alternative to predict difficult intubation. ${ }^{[12,13]}$

Similarly, in their study by Naim et al (2014), they concluded that NC/TM ratio had sensitivity of $100 \%$ and a negative predictive value of $82 \%$ than the Mallampati score with sensitivity of $90 \%$ and specificity of $61 \%$.[12] Similarly, Kim et al (2011) considered NC/TMD to be a better predictor in obese patients than already existent ones.[13] They concluded that NC/TMD is a better indicator than either the $\mathrm{NC}$ or TMD alone. The reason in difference of sensitivity and specificity could be that probably our study did not include the obese patients. Regarding Mallampati grading, many of the previous studies have shown different sensitivities and specificities. Mallampati was found to be an independent predictor.[14] Mallampati score has good sensitivity of $89.6 \%$, but low specificity of $75 \%$ as compared to RHTMD. This result is consistent with the study of Anna Lee et al (2006). They concluded that the Mallampati tests have limited accuracy in predicting the difficult airway and thus are not valuable screening tests in non-obese patients.[14]

Rationale behind variability of results for Mallampati in various studies as well as in our study could be because of observer's variability, so results may vary with different observer. Phonation during examination also alters the score. 
While in RHTMD measurement, RHTMD is based on precise measurement method of individual body proportions. So it could be a sturdy indicator.

We found that ratio of NC/TMD and RHTMD were better predictors of difficult intubation compared to other predictors. For RHTMD, value of 25 was found to be the optimal cut-off value to predict difficult laryngoscopy in Caucasian population, while cut-off in our study was 21.6.[9] In one of the studies done by Krishna et al (2005) which was done in Indian population, cut-off value was $21.3 \mathrm{~cm} .{ }^{[15]}$ Balakrishnan and Chockalingam (2017) in their study concluded a cut-off value of 17.1,[16] which was lower than our study population and in other Indian studies.[15,17,18] Probably, their study had predominantly female population and used TMD cut-off at $(9.03 \pm 1.2)$, which was 6.5 in our population. So it can be concluded that it could be a better predictor than TMD or Mallampati in Indian population too, though cut-off values have come out to be lower than Caucasians or western population. But larger sample size is required to come to an absolute value of cut-off.

\section{Limitations of Study}

In many recent trials, RHTMD is found to be a good indicator. ${ }^{[8,9]}$ But it has few limitations too. It is not a simple method to do. One needs to do accurate measurement of patient's height and thyromental distance. Moreover till now cut-off values are race dependent, the cut-off value may not be applicable to other population. So we tried to find out in Indian population, specifically north Indian population. More studies are required from different places of India with adequate sample size to come to any absolute value of cut-off, because Indian population itself includes diversity of races.

\section{CONCLUSION}

These two predictors NC/TMD and the ratio of patient's height to thyromental distance have a better predictive value than the thyromental distance or Mallampati grading for difficult intubation. If subjected to further researches with large sample size, RHTMD can be a new indicator with absolute cut-off value, especially in non-obese patients.

\section{REFERENCES}

[1] Shiga T, Wajima Z, Inoue T, et al. Predicting difficult intubation in apparently normal patients: a metaanalysis of bedside screening test performance. Anesthesiology 2005;103(2):429-37.

[2] Mallampati SR, Gatt SP, Gugino LD, et al. A clinical sign to predict difficult tracheal intubation: a prospective study. Can Anaesth Soc J 1985;32(4):429-34.

[3] Samsoon GL, Young JR. Difficult tracheal intubation: a retrospective study. Anaesthesia 1987;42(5):487-90.

[4] Wilson ME, Spiegelhalter D, Robertson JA, et al. Predicting difficult intubation. $\mathrm{Br} \mathrm{J}$ Anaesth 1988;61(2):211-6.
[5] Adnet F, Borron SW, Racine SX, et al. The intubation difficulty scale (IDS): proposal and evaluation of a new score characterizing the complexity of endotracheal intubation. Anesthesiology 1997;87(6):1290-7.

[6] Cormack RS, Lehane J. Difficult tracheal intubation in obstetrics. Anaesthesia 1984;39(11):1105-11.

[7] Garg R, Dua CK. Identification of ideal preoperative predictors for difficult intubation. Karnataka Anaesth J 2015;1(4):174-80.

[8] Rose DK, Cohen MM. The airway: problems and predictions in 18, 500 patients. Can J Anaesth 1994;41(5 Pt 1):372-83.

[9] Schmitt HJ, Kirmse M, Radespiel-Troger M. Ratio of patient's height to thyromental distance improves prediction of difficult laryngoscopy. Anaesth Intensive Care 2002;30(6):763-5.

[10] Gonzalez H, Minville V, Delanoue $\mathrm{K}$, et al. The importance of increased neck circumference to intubation difficulties in obese patients. Anesth Analg 2008;106(4):1132-6.

[11] Brodsky JB, Lemmens HJ, Brock-Utne JG, et al. Morbid obesity and tracheal intubation. Anesth Analg 2002;94(3):732-6.

[12] Naim HEA, Mohamed SAR, Soaida SM, et al. The importance of neck circumference to thyromental distance ratio (NC/TM) as a predictor of difficult intubation in Obstructive Sleep Apnea (OSA) patients. Egyptian J Anaesth 2014;30(3):219-25.

[13] Kim WH, Ahn HJ, Lee CJ, et al. Neck circumference to thyromental distance ratio: a new predictor of difficult intubation in obese patients. $\mathrm{Br} \mathrm{J}$ Anaesth 2011;106(5):743-8.

[14] Lee A, Fan LT, Gin T, et al. A systematic review (metaanalysis) of the accuracy of the Mallampati tests to predict the difficult airway. Anesth Analg 2006;102(6):1867-78.

[15] Krishna HM, Agarwal M, Dali JS, et al. Prediction of difficult laryngoscopy in Indian population: role of ratio of patient's height to thyromental distance. J Anaesthesiol Clin Pharmacol 2005;21(3):257-60. https://manipal.pure.elsevier.com/en/publications/p rediction-of-difficult-laryngoscopy-in-indianpopulation-role-of

[16] Balakrishnan KP, Chockalingam PA. Ethnicity and upper airway measurements: a study in South Indian population. Indian J Anaesth 2017;61(8):622-8.

[17] Badheka JP, Doshi PM, Vyas AM, et al. Comparison of upper lip bite test and ratio of height to thyromental distance with other airway assessment tests for predicting difficult endotracheal intubation. Indian J Crit Care Med 2016;20(1):3-8.

[18] Prakash S, Kumar A, Bhandari S, et al. Difficult laryngoscopy and intubation in the Indian population: an assessment of anatomical and clinical risk factors. Indian J Anaesth 2013;57(6):569-75. 